Scottish Landowners' Federation, continued principally in Glenesk, Angus, but to a subsidiary extent on half a dozen other moors. The Conservancy has also joined with other interested parties in Scotland in preparing a scientific and humane scheme for the control of red deer which should clear the way to remedy conditions which are a national reproach.

In dealing with the acquisition and declaration of nature reserves, the report refers in some detail to the Isle of Rhum and to St. Kilda, and reproduces the public statement relating to public access to Rhum issued in July. A primary purpose of acquisition is scientific research, and this is one of the few suitable areas in the Highlands where such research can be undertaken without interference with existing uses. The programme contemplated includes controlled experiments on the effects of burning and vegetation recovery, on run-off of water, on the diet and habits of red deer and particularly on the possibilities of restoring tree cover and planting shelter belts. It thus aims at the balanced long-term development of the natural resources of the island for scientific research and training, nature conservation and meat production. The reference to $\mathrm{St}$. Kilda is of particular interest as showing how, given goodwill and a determination to help both sides, a major Services operation on ethnological and wildlife research can proceed in perfect harmony.

During the year the arrears of notification of owners of areas of special scientific interest were finally eliminated in England, but in Wales even greater difficulties have been exporienced in tracing the owners of some sites. In the seven years since the surveys were made on which the scheduling of the first English sites was based, conditions have in some instances changed, and at present no habitat type seems more threatened than Chalk grassland, where a re-assessment is urgently needed to protect the best remaining areas which are the refuge of many rare or local species of plants, insects and molluses. The Conservancy has been obliged to press the strongest opposition to the project of the Tees Valley Water Board for reservoirs in Upper Teesdale, which cannot be reconciled with the conservation of an area characterized not only by the wealth of rare plants but also by an assemblage of species repre. senting a wide range of geographical elements and their importance in post-glacial vegetation studies.

The present state of public knowledge of, and response to, the Protection of Birds Act, 1954, is still inadequate to fulfil the intentions of the Act; and the Nature Conservancy, in co-operation with the Royal Society for the Protection of Birds, has sought to give publicity of the provisions of the Act as well as to check unwise publicity about rare birds. The licensing system regarding the killing of wild birds appears to work smoothly, and in February 1957 the Conservancy held a small exploratory meeting of scientists immediately concerned with the diurnal birds of prey to discuss the present state of knowledge generally, whether any interrelation between predators and food is discernible and what is known of the biological role of birds of prey.

\title{
EVOLUTION AND THE COMMON MAN
}

$\mathrm{P}_{\mathrm{R}}^{\mathrm{R}}$ RIOR to a recent television series on evolution, the producer asked the Audience Research Department of the B.B.C. to equip him with information about the knowledgeability of potential viewers, their attitude towards evolution and, in particular, how far they believe there to be any conflict between the theory of evolution and other ways of looking at the origin of life, such as that set out in the Old Testament.

Of the 240 London viewers who took part in a series of discussions which were arranged at Broad. casting House, nearly half thought that evolution was connected with 'change', 'progress' or 'development', and half of these specified the process of change in physical things, in life, mankind or species. One in ten made a point of the gradualness of the changes involved. Slightly more mentioned that evolution was concerned with 'the origin of things', though this was not always with living matter or species or man. A third of the sample were unable to volunteer any statement at all.

Viewers were asked whom they associated with evolution. One in three could give no name; the name given by far the most (by one-third of the total) was that of Darwin. A few mentioned Huxley-but as many named Einstein. Other suggestions ranged from Aristotle to Attenborough, or Marconi to Mortimer Wheeler.

The groups were then given the names of a few selected persons whom they might rightly associate with the theory of evolution (Darwin, Huxley, Wallace and Mendel) and they were then asked how these reople got their ideas and what they did.
About half the viewers were unable to venture any answer to this question. Of those who could, a fifth gave the title of one of Darwin's books, if not always accurately. An equal number said that "they came out with a theory" ; and most of these identified the theory as indicating that "man is descended from monkeys", a few giving a more cautious and accurate version. Rather more than one in ten mentioned that the people who worked on evolution study the evidence; and half the viewers referred to specific evidence such as skulls or fossils or rocks. Most of the rest mentioned "studying life generally", "travelling far and wide", "The Beagle" or "studying other writings on the subject" as the source of ideas.

Viewers were asked how they thought 'the leaders', the people in important positions, felt about evolution. Those who replied fell into four roughly equal groups. One thought the idea of evolution to be generally accepted by 'the experts', the second thought that 'the leaders' were unconcerned about the subject, the third that they were of quite divided opinions, and the remaining group referred to disagreement between church leaders and others or the attempt to reconcile the religious view with the scientific view.

About two-thirds of the sample of viewers said they themselves believed in evolution; just over a tenth disbelieved the theory, the remainder having no firm opinions. Of those who said they believed in evolution, almost half were unable to advance a reason for doing so. More than a fifth said no more than that it was the "most tenable theory", but almost as many referred to the study of animals, the extinction of 
some species and their change in form as being the major reason for their belief. Rock or fossil evidence, or the study of skeletons and remains was mentioned much less often.

Of those who disbelieved in the theory, about half gave their belief in God as the prime reason. Other reasons put forward by very small minorities of the total sample were "because believing in the religious view is the best thing", "because I am a Roman Catholic", or "because I just don't believe it".
Asked what would ultimately happen to man, almost half the viewers were not prepared to volunteer any answer. The replies of those who did were diffuse. In descending order of frequency the forecasts were : (1) that man would suffer destruction at his own hands; (2) that he would increase his power and conquer space; (3) that there would be development of brain power, or that man would lose certain parts, such as his toes. A few thought man to be "at his peak" and not likely to change further.

\title{
CHEMICALS DISSOLVED IN RAIN WATER
}

$\mathrm{T}$ HE study of the nature of the chemicals dissolved in rain water is important to the agriculturalist and botanist because of their effect in the nutrition of plants and to the meteorologist for the light thrown on the physics of rain formation and on atmospherie diffusion.

Much work has been done on this matter in Sweden in recent years. There it has been found that very near the coast the predominant elements are sodium and chlorine in nearly the same ratio as in sea water (sodium/chloride ratio 0.85 ) but that inland the proportion of sodium increases rapidly. No satisfactory reason for this increase inland has been put forward.

Mr. E. Gorham, of the Freshwater Biological Association, Ambleside, Westmorland, has recently published* similar analyses of precipitation falling at a point on Hawkshead Moor during January 1955January 1956.

$\mathrm{He}$ found a close correlation between the amounts of sodium and chlorine, with a ratio of sodium to chloride almost the same as that in sea water, and also a close connexion between the amounts of hydrogen, potassium, calcium, nitrate and sulphate ions. There was a remarkably clear association between the chemical constitution of the solutes and wind direction. Rain falling with south-westerly winds contained much more chloride than that with winds from other directions, and similarly, rain with southeasterly winds contained much higher amounts of sulphate and nitrate. The latter effect is naturally attributed to atmospheric pollution from the industrial areas to the south-east of the site. Comparison of

* Philosophical Transactions of the Royal Society of Lomdon. Series B : Biological Sciences. No. 679, Vol. 241 (9 January, 1958): The Infiuence and Importance of Daily Weather Conditions in the Supply of Chloride, Sulphate and other Ions to Fresh Waters from Atmospheric Precipitation. By E. Gorham. Pp. 147-178. (London: Roya) Society, 1958.) 108 . hydrogen-ion concentration and sulphate plus nitrate concentration shows that hydrogen and sulphate are largely combined as sulphuric acid. The ratio of sodium to chloride did not, however, vary with wind direction in the way that would have been expected from the Swedish observations. The amounts of both chloride and sulphate plus nitrate increased with wind speed, the observed variation being a tenfold increase for the first and two-fold for the second. This supports the sea-spray theory of the principal source of atmospheric chloride and agrees with observations at Hawaii.

A further result is that rain, in which the ratio of sodium to chloride was less than 0.8 , fell predominantly with easterly winds containing a high proportion of sulphate. This suggested that some chloride is supplied by atmospheric pollution, and a study of the chloride in smoke solids collected by filters in London buildings is found to support this theory. The opposite phenomenon of excess sodium values, the criterion being a sodium chloride ratio of 0.95 , occurred in small showers, the highest value of excess sodium occurring in a hail shower. It was first thought that the excess sodium might be produced in these showers by local rock dust, but analysis of lake waters which might equally be expected to show the same effect did not support the hypothesis. Taking the hint from the hail shower, the author then carried out an experiment to see if chemical reaction between sulphuric acid and sodium chloride leading to production of gaseous hydrochloric acid were facilitated by freezing. This was found to be the case, and he suggests that it is possible that excess sodium occurs because the increase in concentration of the solutes brought about by freezing leads to production and subsequent escape of hydrochloric acid.

\section{OXIDATIVE PHOSPHORYLATION : A CHEMICAL APPROACH USING QUINOL PHOSPHATES}

\author{
By DR. V. M. CLARK, G. W. KIRBY and SIR ALEXANDER TODD, F.R.S. \\ University Chemical Laboratory, Cambridge
}

$\mathrm{T}$ THE ubiquitous occurrence of phosphate and polyphosphate esters in biological systems has, in recent years, stimulated widespread interest in problems of chemical phosphorylation'. For the solution of such problems, the phosphorus atom of the phosphorylating agent must be the centre for nucleophilic attack ${ }^{2}$ and with the common reagents, for example, the phosphorochloridates ${ }^{3}$ and pyrophosphates $^{4}$, acylation proceeds with the expulsion of an anion (reactions $1,2,3$ ).

The phosphoramidates, another type of reagent, require to be in the zwitterionic form to exhibit their acylating function, the expelled group then being a neutral amine molecule (reaction 4). 